\title{
Impacts of reduced anthropogenic activities on black carbon concentration and related atmospheric parameters at an urban metropolis near the land ocean boundary during COVID-19 pandemic
}

\author{
Soumyajyoti Jana, Gargi Rakshit and Animesh Maitra* \\ Institute of Radio Physics and Electronics, University of Calcutta, 92, Acharya Prafulla Chandra Road, Kolkata 700 009 , India
}

\begin{abstract}
The ongoing COVID-19 pandemic necessitated a complete lockdown from 24 March to 31 May 2020 as imposed by the Government of India to prevent the spread of the virus that resulted into halting most of the economic activities during that period. The stringent anthropogenic activities during the lockdown phase resulted in a notable drop in the air pollution level. The prevailing global scenario during the pandemic has provided an opportunity of assessing the air quality in the absence of normal anthropogenic activities. In the present article, the impacts of reduced anthropogenic activities on the black carbon concentration and associated atmospheric parameters have been studied over a tropical urban location, Kolkata $\left(22.57^{\circ} \mathrm{N}, 88.37^{\circ} \mathrm{E}\right)$ in eastern India. Investigations have been made on the impacts on the parameters like atmospheric electric field, wind speed, temperature, relative humidity, dew point temperature, rain accumulation and soil moisture during this unusual time in comparison to the same time span of the previous year 2019 when the usual human activities were pursued.
\end{abstract}

Keywords: Atmospheric parameters, black carbon, COVID-19 lockdown, rainfall, soil moisture, wind speed.

\section{Introduction}

PARTIAL lockdown measures to prevent the spread of the coronavirus were imposed over the present study location from the mid of March 2020 by the local state government. However, nationwide complete lockdown commenced from 24 March 2020 and extended up to the end of May 2020. Though this imposed lockdown resulted in social disruption and slowing down of economic growth, at the same time it resulted in an unprecedented reduction of pollution level. The pre-monsoon period prevails during March-May over the study location when the lockdown occurred. So for the present study the whole

\footnotetext{
*For correspondence. (e-mail: animesh.maitra@gmail.com)
}

pre-monsoon period is considered to investigate the prevailing aerosol environment in terms of black carbon (BC) concentration and associated atmospheric parameters. Atmospheric $\mathrm{BC}$ which is generated from the incomplete combustion significantly contributes to atmospheric warming by absorbing a wide spectral band of radiation ${ }^{1,2}$. Also it is considered as an important agent in global warming after $\mathrm{CO}_{2}$ (ref. 2). For an urban tropical location like Kolkata, which is a highly polluted and densely populated city with heavy traffic loads and industrial activities, $\mathrm{BC}$ is the major polluting agent. On one hand high $\mathrm{BC}$ concentration causes cloud burn-off and on the other it causes cooling effect on the surface, and as a result impacts the temperature profile and subsequent cloud genesis and precipitation ${ }^{3,4}$. Definite patterns of both diurnal and seasonal variation of black carbon have been reported from various parts of India including the present study location $\mathrm{Kolkata}^{5-8}$. In addition, the presence of $\mathrm{BC}$ is seen to have modulated the diurnal variation of atmospheric electric field over the urban polluted location ${ }^{9}$. The stringent anthropogenic activities over the study location during the COVID-19 pandemic have resulted in very low emission of BC and thereby impacted the local atmospheric conditions. So, the present study is concerned with the alteration of the diurnal variation of black carbon, atmospheric electric field and associated atmospheric parameters like wind speed, relative humidity, and dew point temperature. The changes in the rain accumulation and soil moisture have also been assessed during the lockdown period in comparison to the same period of the previous year.

\section{Data, instruments and methodology}

The present study utilizes the data of ground-based and space-borne measurements discussed below.

A seven channel Aethalometer (AE 31) of the Magee Scientific Company, USA is operated at the Institute of Radio Physics and Electronics, University of Calcutta, 
Kolkata $\left(22.57^{\circ} \mathrm{N}, 88.37^{\circ} \mathrm{E}\right)$ measuring the mass concentration of $\mathrm{BC}$ particles. It samples the ambient air from the atmosphere at a temporal resolution of $5 \mathrm{~min}$ through a cyclone inlet at a constant flow rate of $41 / \mathrm{min}$. The BC particles are deposited on the quartz filter tape through which the sampled air is allowed to pass. Among the seven wavelengths (namely 370, 470, 520, 590, 660, 880, $950 \mathrm{~nm}), 880 \mathrm{~nm}$ is utilized for standard BC measurement as it is closest to the $830 \mathrm{~nm}$ wavelength at which $\mathrm{BC}$ has the maximum absorption ${ }^{10}$.

The data of atmospheric parameters like dew point temperature, relative humidity and wind speed have been obtained from an automatic weather station (AWS) of Theta Instruments (Model: MP650) operated at the present location. The data are available at a temporal resolution of $1 \mathrm{~min}$.

Atmospheric electric field variation over Kolkata is estimated from the measurements of an electric field mill (EFM-100) operated in the present study location in Kolkata. The EFM uses a mechanical chopper to alternately shield and expose several sense plates to the atmospheric electric field creating an alternating current voltage across a resistor, the magnitude of which is proportional to the amount of electric field applied to the sense plates $^{11,12}$. The frequency of the measurements utilized in the present study is $20 \mathrm{~Hz}$. Clear day electric field data are obtained for the present study.

The rain events during the study period are identified from the rain rate measurements using a laser precipitation monitor (LPM) operated over the present location. The ThiesClima LPM is a ground based contactless instrument to measure the rain parameters like rain rate, drop size, rain accumulation and fall velocity simultaneously using a $780 \mathrm{~nm}$ wavelength laser beam with a cross-sectional area of $46 \mathrm{~cm}^{2}$. The diameter of a falling hydrometeor is measured from the reduced signal amplitude and the fall velocity from the duration of the reduced signal. Being a contactless instrument, the errors introduced due to retention and evaporation are absent in LPM observations making it a fairly robust and accurate instrument ${ }^{13}$. Rain accumulation data have been obtained from LPM during the pre-monsoon period of 2019 and 2020 with 1 min temporal resolution.

The reanalysis data of soil moisture used for present study are obtained from ECMWF (European Centre for Medium-Range Weather Forecasts) available from the Copernicus data centre. This dataset is the compilation of a large set of satellite sensors which provides estimates of soil moisture over the globe at a spatial resolution of $0.125^{\circ} \times 0.125^{\circ}$ available daily. The data over the grid point of $\left(22.625^{\circ} \mathrm{N}, 88.275^{\circ} \mathrm{S}\right)$ are considered for the present study. Soil moisture data are used to observe the effect of a changing rain environment in 2020 compared to 2019 .

Hourly ERA-5, near surface temperature (2 metre) data obtained from ECMWF data archive available at a spatial resolution of $0.25^{\circ} \times 0.25^{\circ}$ around the grid point covering the present study location is utilized in the study.

\section{Results and discussions}

\section{Variation of BC and its impact on electric field variation}

The change in $\mathrm{BC}$ concentration due to the lockdown is assessed over the study location Kolkata in contrast to the BC concentration of the previous year 2019 as the base year. Figure 1 shows the mean diurnal variation of the clear day BC during the pre-monsoon months, March, April and May for 2019 and 2020. It is seen from Figure 1 that during the year 2020 black carbon concentration over the study location has decreased drastically in comparison to the $\mathrm{BC}$ concentration of the year 2019. The overall reduction in $\mathrm{BC}$ is also significant from March (Figure $1 a$ ) to May (Figure $1 c$ ) during 2020. BC values shown in the form of diurnal variation are least during May (daily mean varying between 0.6 and $0.8 \mu \mathrm{g} / \mathrm{m}^{3}$ ) compared to March (mean 3.5-4.8 $\mu \mathrm{g} / \mathrm{m}^{3}$ ) and April (mean $0.8-1.5 \mu \mathrm{g} / \mathrm{m}^{3}$ ) of the year 2020 . The average diurnal variation of $\mathrm{BC}$ during clear days for each premonsoon month for 2019 shows prominent morning and evening peaks as already reported earlier from the present location $^{7-9}$. The morning peak in the $\mathrm{BC}$ is due to the increased anthropogenic activities and also the fumigation effect in the atmospheric boundary layer which occurs after the local sunrise ${ }^{14}$. The black carbon concentration decreases during the noon time due to increased local convection in association with expansion of the atmospheric boundary layer (ABL) and dispersion of aerosols within ABL. However, after sunset lowering of the ABL gradually occurs which confines $\mathrm{BC}$ to the near surface level, resulting in an enhancement of the ground-based BC measurements ${ }^{15}$.

A contrasting diurnal behaviour of $\mathrm{BC}$ concentration is noticed during the pre-monsoon months of 2020. The morning peak of the $\mathrm{BC}$ has almost flattened, more clearly during April and May which is the effect of stringent restrictions on the transport, industries and commercial sectors due to the lockdown. Figure 2 shows the mean diurnal variation of $\mathrm{BC}$ concentration for all pre-monsoon months during 2019 and 2020. The evening peak is more prominent (shown enlarged in Figure 2) than the morning peak during 2020.

It is known that the local aerosols environment regulates the fair-weather atmospheric conductivity at a place $^{16,17}$. The reason behind this is that the aerosol particles attach with the small ions present in the atmosphere, produced by the cosmic ray and terrestrial radioactivity to convert into large ions with reduced mobility. Thus, it can be said, high urban pollution enhances the atmospheric electric field value by decreasing the ion 


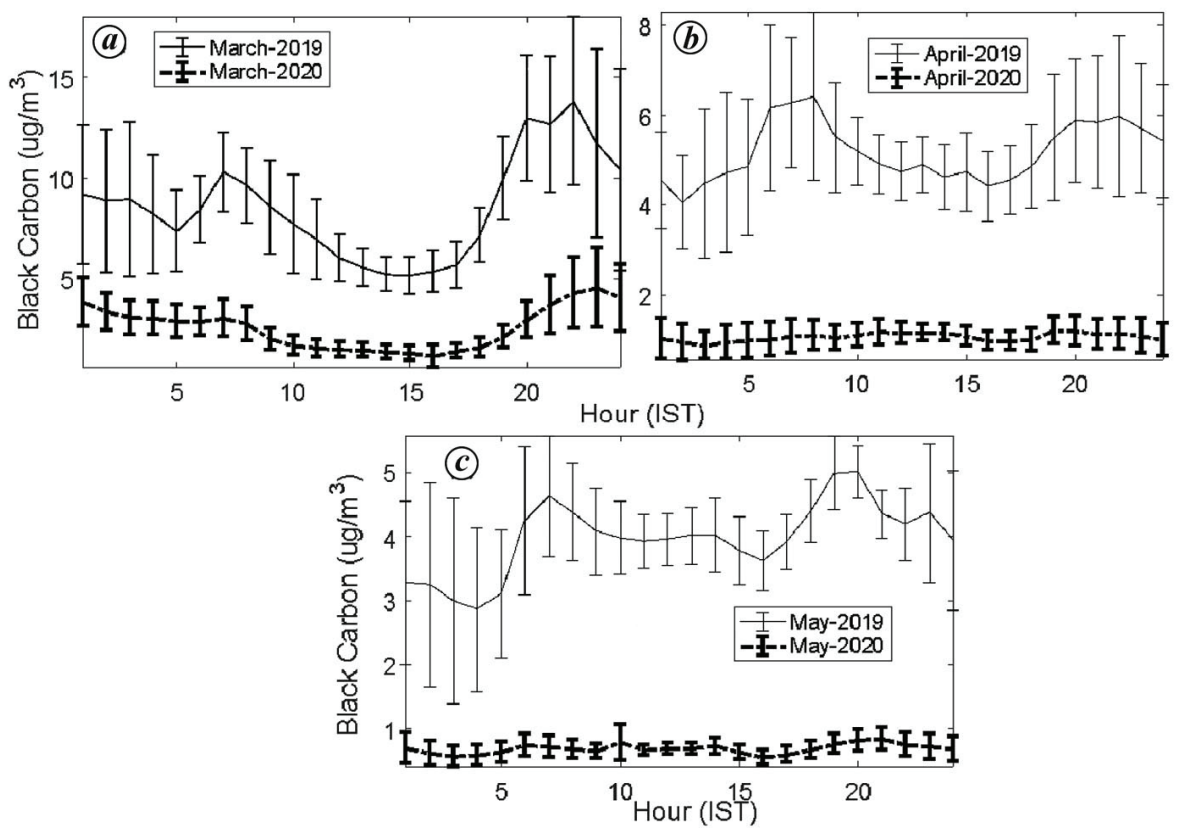

Figure 1. Mean diurnal variations of $\mathrm{BC}$ concentration (with standard deviations) in the pre-monsoon months.
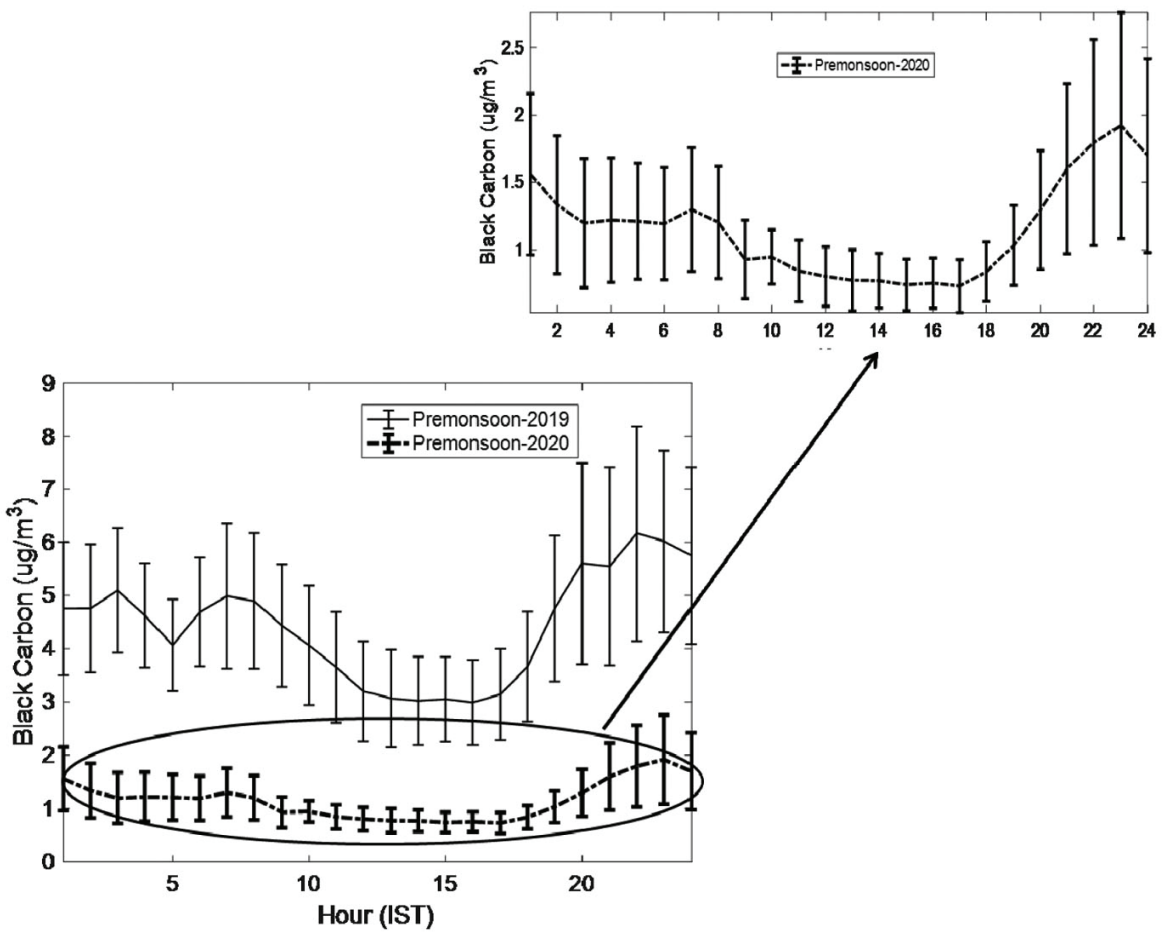

Figure 2. Mean diurnal variations of $\mathrm{BC}$ concentration (with standard deviations) in the pre-monsoon season (March-May) during 2019 and 2020. The mean diurnal variation of BC concentration during 2020 is enlarged in a separate figure to reveal the variability more prominently.

mobility which in turn reduces the conductivity of the atmosphere. In this context, a previous study from the present study location showed significant correlation of the clear days atmospheric electric field with $\mathrm{BC}$ concentration'. However the restricted anthropogenic activities during the lockdown due to COVID-19 pandemic, the BC concentration drastically decreased over the present study location. This provides a unique opportunity to assess the atmospheric electric field behaviour in this unusual situation over the urban metropolis. Mean diurnal behaviour 


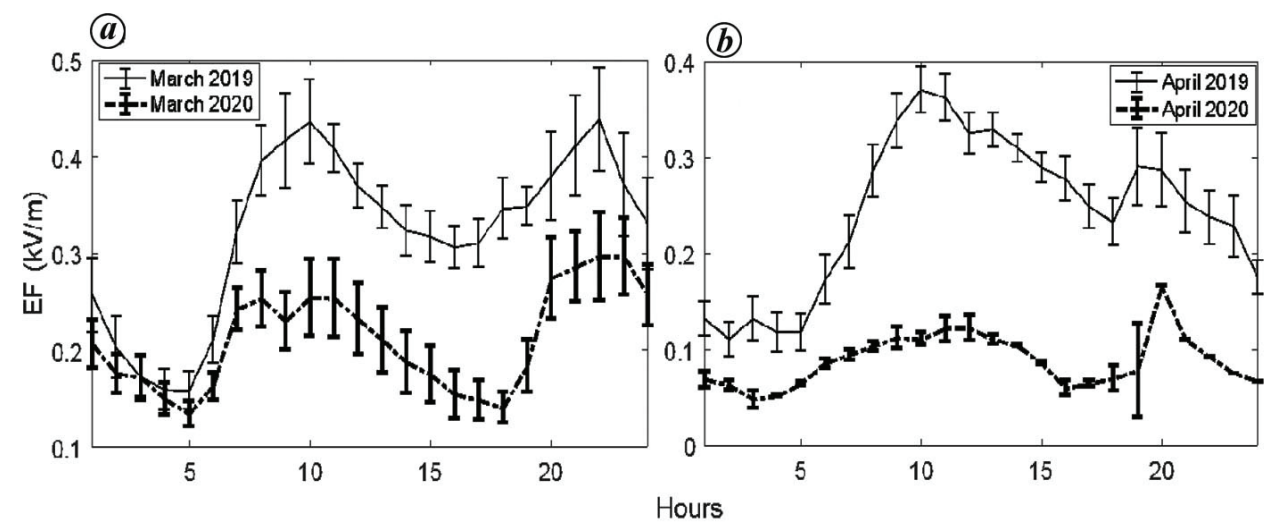

Figure 3. Mean diurnal variation of electric field $(\mathrm{kV} / \mathrm{m})$ (with standard deviations) in the pre-monsoon months.

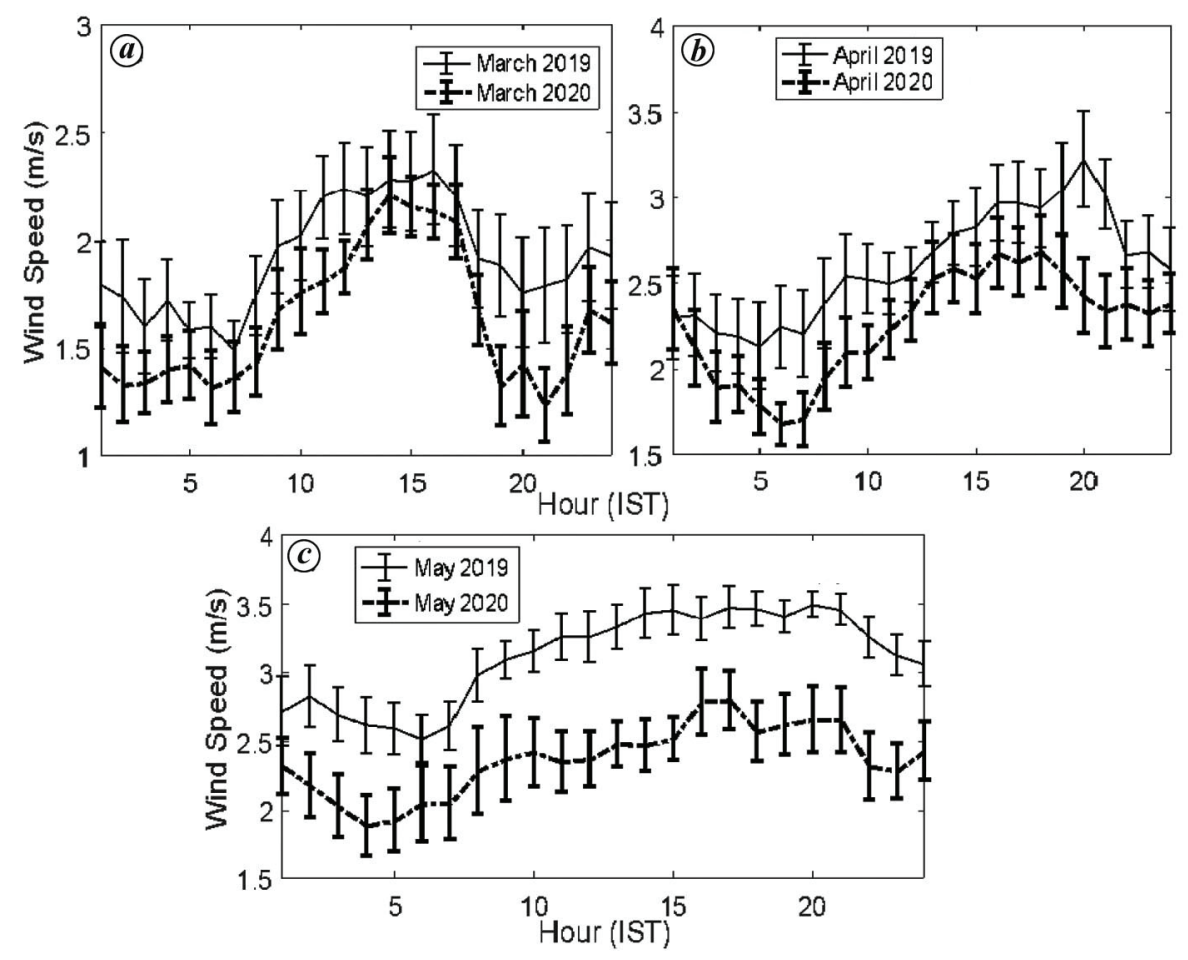

Figure 4. Mean diurnal variations of wind speed (with standard deviations) in the pre-monsoon months.

of the electric field during the lockdown months has been compared with respect to the same period of the previous year 2019. Figure 3 shows that though the nature of diurnal variation of clear-day atmospheric electric field followed the previous year 2019, the magnitude of the electric field during the pre-monsoon months March and April (the data of May is not available) has over all decreased in 2020 over Kolkata. The decrease in the electric field value is more prominent during April than that in March 2020 which is in commensurate with the $\mathrm{BC}$ concentration changes. This shows that, due to the reduced $\mathrm{BC}$ concentration, the magnitude of the atmospheric electric field has decreased over the present location.

\section{Variation of associated atmospheric parameters}

The effect of the changing $\mathrm{BC}$ environment is supposed to have impacts on the basic atmospheric parameters over the study location. Previous studies have revealed that during pre-monsoon months high wind speeds which prevail over the study location increase the ventilation process, lowering the $\mathrm{BC}$ concentration ${ }^{8,18}$. The mean diurnal behaviour of monthly wind speed during the premonsoon months of 2019 and 2020 is shown in Figure 4. It is revealed that the average horizontal wind speed was lower during the lockdown phase over Kolkata compared to the same time period of the previous year. This is possibly due to reduction in horizontal temperature gradient 


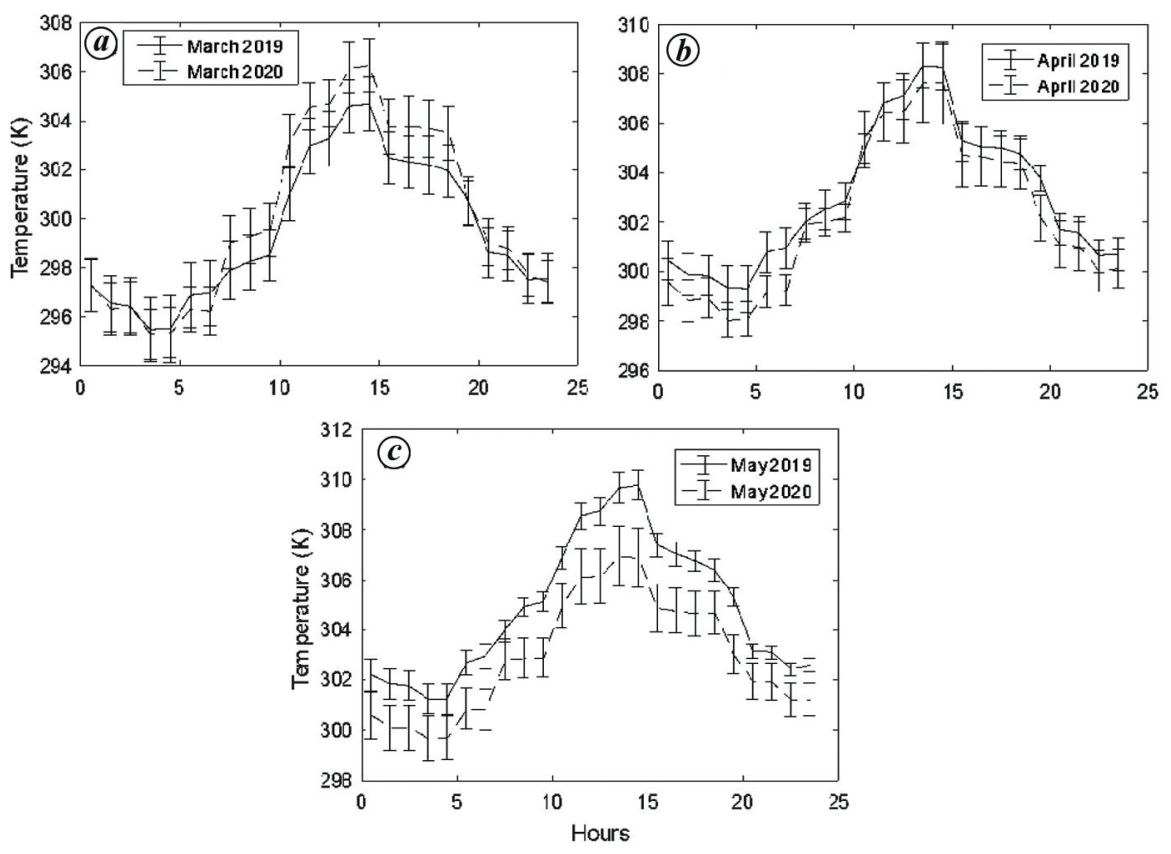

Figure 5. Diurnal temperature variations in the pre-monsoon months.

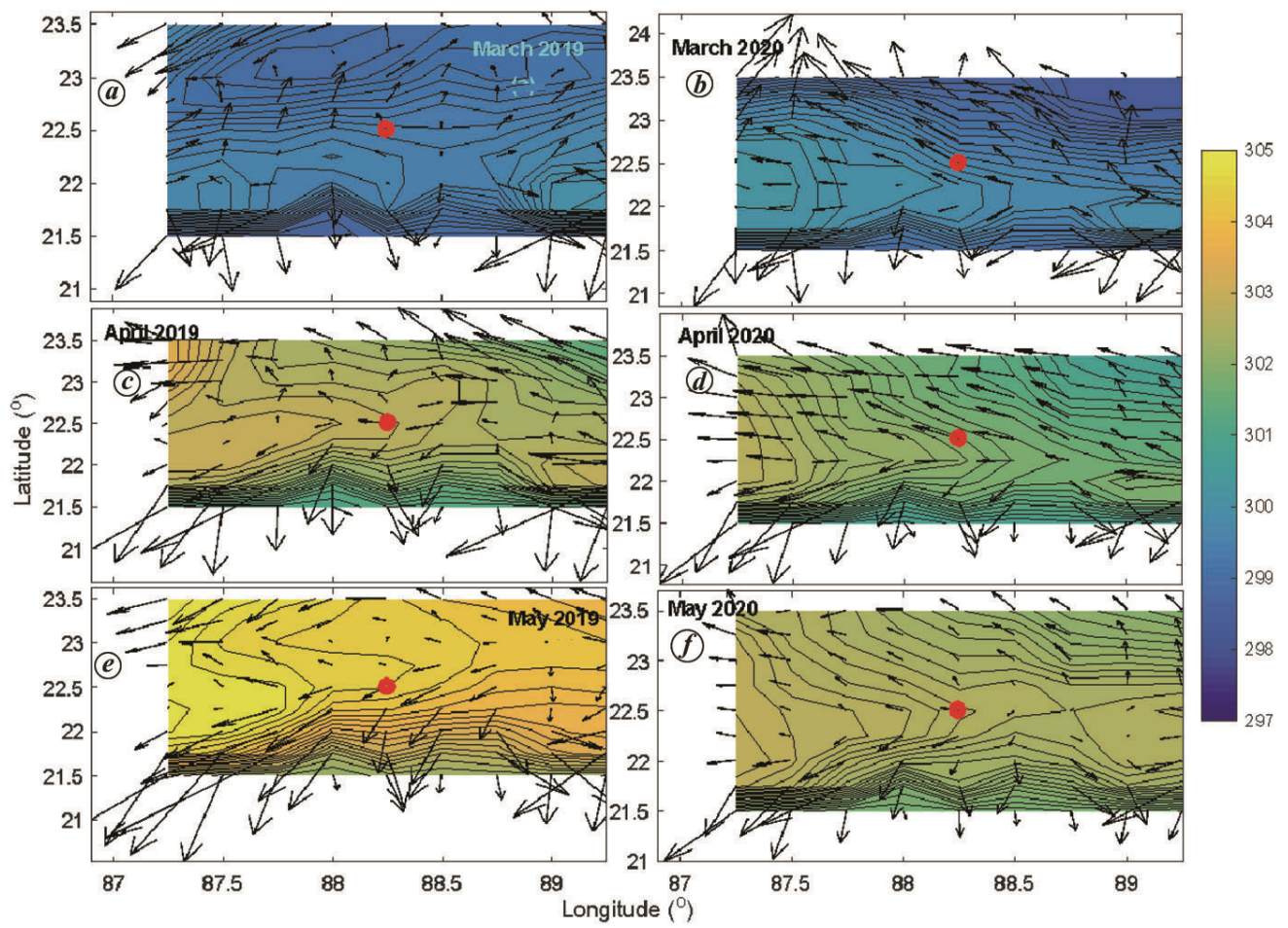

Figure 6. The monthly temperature around the study location with the temperature gradient calculated at every grid point. The red filled circle indicates the location of Kolkata. The colour bar represents the temperature in Kelvin

caused by low presence of heat-absorbing aerosols. In spite of low wind speed during pre-monsoon months of 2020 , the BC concentration was very low as the sources of the $\mathrm{BC}$ generation were almost absent during the lockdown period owing to restricted anthropogenic activities.
The decrease of wind speed could be the cause of decreased temperature and spatial temperature gradient. In this connection, the hourly temperature data from ECMWF ERA-5 data archive has been processed to determine the monthly diurnal variation of temperature 

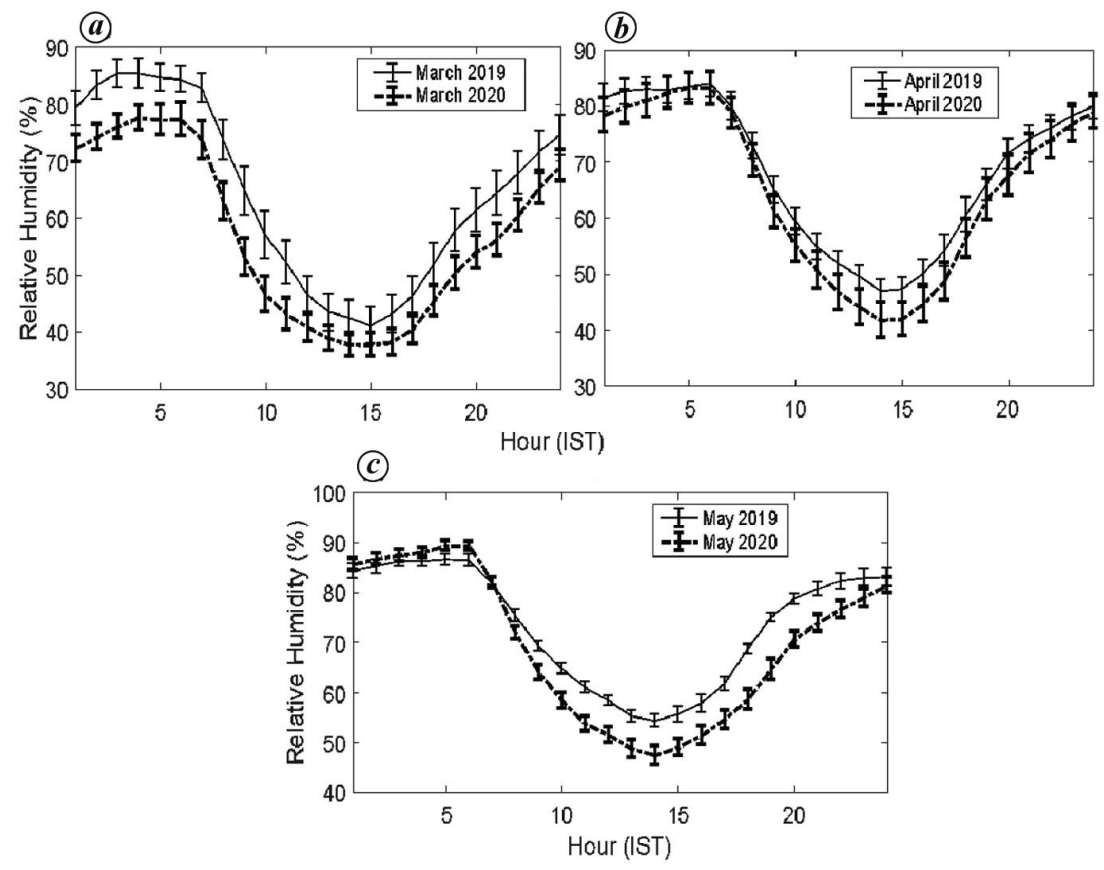

Figure 7. Mean diurnal variations of relative humidity (with standard deviations) in the pre-monsoon months.

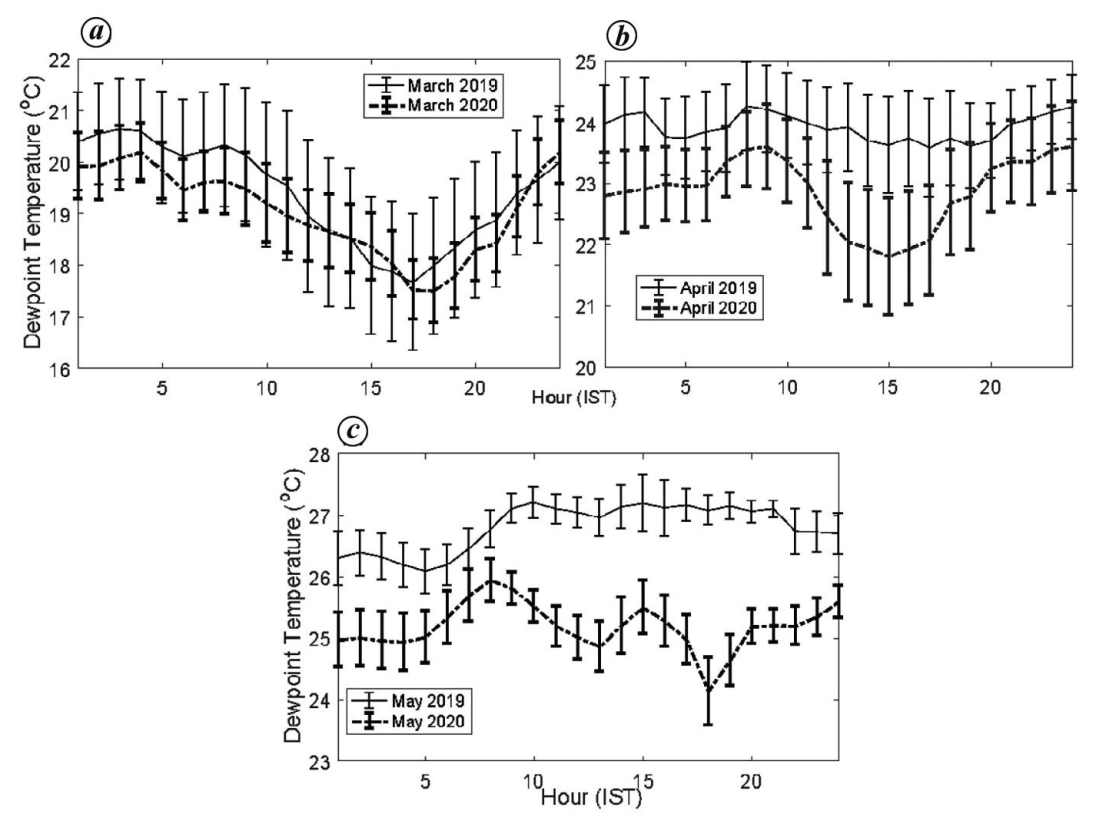

Figure 8. Mean diurnal variations of dew-point temperature (with standard deviations) in the pre-monsoon months.

during the pre-monsoon months (Figure 5). Also, the spatial temperature has been plotted with the spatial temperature gradient in Figure 6.

Figure 5 shows that the temperature has decreased significantly from March to May in 2020 compared to 2019. Figure 6 depicts that the contour plot of the spatial temperature around Kolkata (indicated by red filled circle), indicated by the ambient contour of the plots, decreases in 2020 compared to the previous year 2019. The black arrows in Figure 6 indicate the spatial temperature gradient calculated at every grid point of the data. The length of the arrow indicates the magnitude of the gradient. The decrease in temperature at and around Kolkata results in the lower wind speed over the study location. The difference in the temperature gradient is particularly prominent during May showing smaller values in 2020 compared to 2019 (Figure $6 e$ and $f$ ) which is in commensurate to the significant decrement in temperature and wind speed 
during May 2020 compared to the previous year (Figure $4 c$ and Figure $5 c$ ).

The mean diurnal variations of surface relative humidity over Kolkata during the pre-monsoon months of 2020 in comparison to 2019 are shown in Figure 7. It is evident from that the overall mean relative humidity over the study location was lower during the lockdown phase in comparison to the previous year. The reduced relative humidity during the pre-monsoon of 2020 over Kolkata is accompanied by low dew point temperature as shown in Figure 8. This confirms that lower absolute humidity or less amount of water vapour was prevailing in the atmosphere during the lockdown days. During the nationwide lockdown period the anthropogenic emission reduced significantly ${ }^{19}$. As a result, the heat capacity of the atmosphere reduces, making the ambience less warm which is responsible for less evaporation from water sources and, consequently, reduced water vapour generation.

As aerosols act as cloud condensation nuclei (CCN), reduced emission of aerosol particles are supposed to have some impact on the cloud forming process. As we

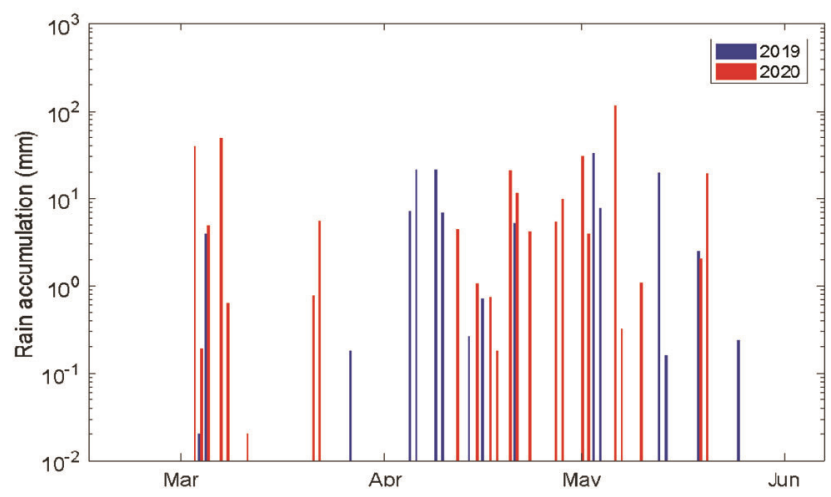

Figure 9. Total rain accumulations during the pre-monsoon months of 2019 and 2020.

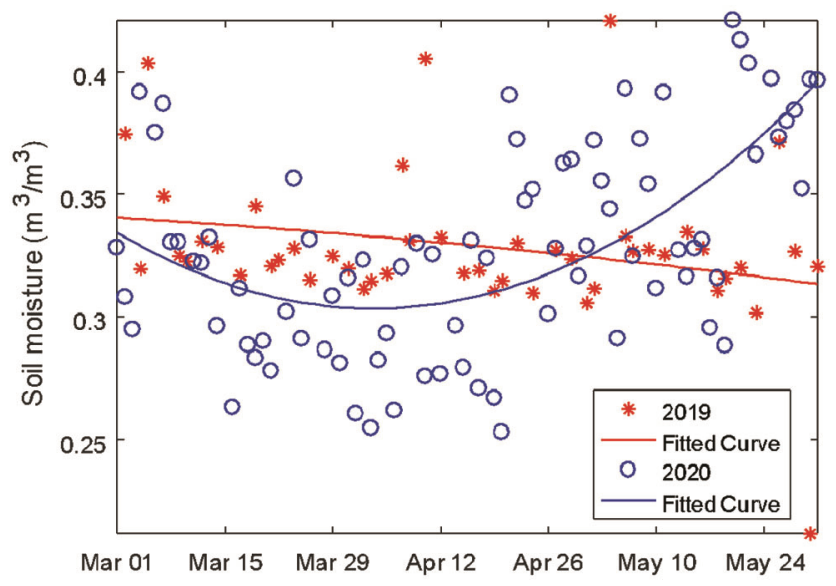

Figure 10. Volumetric soil moisture during the pre-monsoon months of 2019 and 2020. The lines represent 2 nd order polynomial fit. know the presence of a large number of $\mathrm{CCN}$ can hinder the rain forming process, the reduced aerosol generation may help the cloud to rain conversion. Also, BC is a heat absorbing aerosol which can expedite the burn-off process of clouds and suppress rain occurrences. During the lockdown period $\mathrm{BC}$ generation shows significant low values compared to earlier reports. In the light of the above scenario, the rain accumulation at the present location has also been studied using laser precipitation monitor data. Figure 9 shows the daily rain accumulation in 2019 and 2020 in the pre-monsoon period, revealing that the numbers of rainy days are more in 2020 than those in 2019. The total rain accumulation has also increased significantly in the pre-monsoon period of 2020 compared to 2019 (130.34 $\mathrm{mm}$ in 2019 and $330.16 \mathrm{~mm}$ in 2020). The higher rain accumulation and the lesser dry periods in 2020 could increase the soil moisture as well as groundwater recharge. A previous study also showed a close relationship between rainfall amount and soil moisture during monsoon and pre-monsoon period in the Indian region $^{20}$. Earlier reports also confirm positive correlation between precipitation and soil saturation in the different parts of the globe $e^{21,22}$. Accordingly, we studied the reanalysis data of soil moisture from ECMWF Copernicus Data Archive.

The volumetric surface soil moisture $\left(\mathrm{m}^{3} / \mathrm{m}^{3}\right)$ for the pre-monsoon period of 2019 and 2020 is shown in Figure 10. The soil moisture shows a notable increase in May 2020 compared to that during the previous year 2019.

\section{Conclusions}

The article presents the effects of reduced anthropogenic activities on the aerosol environment and related atmospheric parameters over an urban tropical location during the lockdown period due to COVID-19 pandemic. The surface $\mathrm{BC}$ concentration has drastically decreased over the study location impacting the magnitude of the atmospheric electric field. The electric field value over Kolkata is seen to have diminished with the $\mathrm{BC}$ concentrations due to the lesser availability of immobile large ions in the atmosphere. The relative humidity, dew point temperatures have decreased during the pre-monsoon 2020 compared to the previous year. However, the rain accumulation has increased notably during the pre-monsoon 2020 compared to the previous year due to favourable conditions for cloud to rain conversion caused by the reduced presence of aerosols. The soil moisture is seen to have increased during May 2020 compared to May 2019 due to higher rain accumulation.

It is evident that the reduced anthropogenic activities have caused a substantial decrease in BC concentration which has affected other atmospheric parameters such as surface water vapour density, rain accumulation, wind speed, temperature, atmospheric electric field, and soil 
moisture. The study is intended to present a set of atmospheric measurements to demonstrate the impact of reduced aerosol concentrations on the atmospheric processes. This will help us to have a future strategy to address the effects of increased pollution level on the environment and human livelihood once the lockdown is withdrawn.

1. Andreae, M. O. and Crutzen, P. J., Atmospheric aerosols: Biogeochemical sources and role in atmospheric chemistry. Science, 1997, 276, 1052-1056.

2. Ramanathan, V. and Carmichael, G., Global and regional climate changes due to black carbon. Nature Geosci., 2008, 1(4), 221-227.

3. Babu, S. S., Satheesh, S. K. and Moorthy, K. K., Aerosol radiative forcing due to enhanced black carbon at an urban site in India. Geophys. Res. Lett., 2002, 29(18), 27-1.

4. Menon, S., Hansen, J., Nazarenko, L. and Luo, Y., Climate effects of black carbon aerosols in China and India. Science, 2002, 297(5590), 2250-2253.

5. Tripathi, S. N., Dey, S., Tare, V. and Satheesh, S. K., Aerosol black carbon radiative forcing at an industrial city in northern India. Geophys. Res. Lett., 2005, 32(8), L08802.

6. Babu, S. S. and Moorthy, K. K., Aerosol black carbon over a tropical coastal station in India. Geophys. Res. Lett., 2002, 29(23), $13-1$.

7. Talukdar, S., Jana, S. and Maitra, A., Variation of black carbon concentration associated with rain events at a tropical urban location. Curr. Sci., 2014, 107(1), 72-78.

8. Talukdar, S., Jana, S., Maitra, A. and Gogoi, M. M., Characteristics of black carbon concentration at a metropolitan city located near land-ocean boundary in Eastern India. Atmos. Res., 2015, 153, 526-534.

9. Jana, S. and Maitra, A., Electric field variation in clear and convective conditions at a tropical urban location. J. Geophys. Res.: Atmospheres, 2019, 124(4), 2068-2078.

10. Bodhaine, B. A., Aerosol absorption measurements at Barrow, Mauna Loa and the south pole. J. Geophys. Res.: Atmospheres, 1995, 100(D5), 8967-8975.

11. Bloemink, H., Static electricity measurements for lightning warnings - an exploration. INFRA-R\&D, KNMI, 2013; http:// bibliotheek.knmi.nl/knmipubIR/IR2013-01.pdf

12. Ferro, M. A. D. S., Yamasaki, J., Pimentel, D. R. M., Naccarato, K. P. and Saba, M. M. F., Lightning risk warnings based on atmo- spheric electric field measurements in Brazil. J. Aerosp. Technol. Manage., 2011, 3(3), 301-310.

13. Lanzinger, E., Theel, M. and Windolph, H., Rainfall amount and intensity measured by the Thies laser precipitation monitor. TECO-2006, Geneva, Switzerland, 2006, pp. 4-6.

14. Stull, R. B., An Introduction to Boundary Layer Meteorology, Springer, 2012, vol. 13

15. Sreekanth, V., Niranjan, K. and Madhavan, B. L., Radiative forcing of black carbon over eastern India. Geophys. Res. Lett., 2007, 34(17).

16. Harrison, R. G. and Carslaw, K. S., Ion-aerosol-cloud processes in the lower atmosphere. Rev. Geophys., 2003, 41(3).

17. Piper, I. M. and Bennett, A. J., Observations of the atmospheric electric field during two case studies of boundary layer processes. Environ. Res. Lett., 2012, 7(1), 014017.

18. Talukdar, S., Jana, S. and Maitra, A., Dominance of pollutant aerosols over an urban region and its impact on boundary layer temperature profile. J. Geophys. Res.: Atmospheres, 2017, 122(2), 1001-1014.

19. Le Quéré, C., Jackson, R. B., Jones, M. W., Smith, A. J., Abernethy, S., Andrew, R. M. and Friedlingstein, P., Temporary reduction in daily global $\mathrm{CO}_{2}$ emissions during the COVID-19 forced confinement. Nature Climate Change, 2020, 10, 647-653.

20. Varikoden, H. and Revadekar, J. V., Relation between the rainfall and soil moisture during different phases of Indian Monsoon. Pure Appl. Geophys., 2018, 175, 1187-1196.

21. Findell, K. L. and Eltahir, E. A., An analysis of the soil moisturerainfall feedback, based on direct observations from Illinois. Water Resources Res., 1997, 33(4), 725-735.

22. Blume, T., Zehe, E. and Bronstert, A., Use of soil moisture dynamics and patterns at different spatio-temporal scales for the investigation of subsurface flow processes. Hydrol. Earth Syst. Sci., 2009, 13(7), 1215

ACKNOWLEDGEMENTS. This work has been supported by the grants under the projects: (i) 'Studies on aerosol environment at Kolkata located near the land-ocean boundary as a part of ARFI network under ISRO-GBP' (Grant No: SPL:GBP:ARFI:37), (ii) 'Council of Scientific and Industrial Research (CSIR), HRDG (File No: 09/028(1040)/2 018EMR-I)', and (iii) 'UGC Basic Science Research Faculty Fellowship' (No. F.18-1/2011(BSR))

doi: $10.18520 / \mathrm{cs} / \mathrm{v} 120 / \mathrm{i} 2 / 296-303$ 